\title{
ANALISIS FAKTOR-FAKTOR YANG MEMPENGARUHI KEPUASAN \\ PELANGGAN PEMEGANG GARUDA FREQUENT FLYER TERHADAP FASILITAS PELAYANAN DI PT. GARUDA INDONESIA
}

\author{
Novita Wahyu Setyowati dan Yanti Afianti \\ Email: nsetyowati@bundamulia.ac.id
}

\section{Penulis}

Novita Wahyu Setyowati adalah pengajar pada Universitas Bunda Mulia dengan peminatan dalam bidang Manajemen Sumber Daya Manusia.

Yanti Afianti adalah alumnus Program Pasca Sarjana Universitas Krisnadwipayana, Jakarta.

\section{Abstract}

Through the results of a survey study of 70 (seventy) of respondents obtained research results, as follows : Tangible, Confidence, Reliability and empathy are considered valid and contribute positively to the value of R-Square $=98 \%$ and positive prediction, where the parameter estimators obtained ${ }_{Y}^{\wedge}=\alpha+\beta 1 X 1+\beta 2 X 2+\beta 3 X 3+\beta 4 X 4+e$

${ }_{Y}=0,892+1,07 X 1+0,947 X 2+0,98 X 3+0,955 X 4+e$ and significant. $F$ count value $>$ F-table or $712.227>2.557$ for $\alpha=0.05$.

Can be seen that the partial variable Tangible able to give effect to enhance customer satisfaction and are able to contribute positively and can serve as a strong indicator (value of $R$-Square $=80 \%$ ). Positive predictions can be viewed via a probe parameters ${ }_{Y}^{A}=23,036+2,37 X 1+e$ and significant. Value $T$-count $>T$-chart or $4.964>1.7033$ for the degrees of freedom $(D F) \alpha=0.05$.

Confidence can be seen that the partial variables can give effect to enhance customer satisfaction and are able to contribute positively and can serve as a strong indicator (value of $R$-Square $=68 \%$ ). Positive predictions can be viewed via a probe parameters ${ }_{Y}^{A}=12,159+3,18 X 2+e$ and significant. Value T-count $\langle T$-table, or $1.55>1.7033$ for degrees of freedom $(D F) \alpha=0.05$.

Reliability can be seen that the variable is able to give partial effect to enhance customer satisfaction and are able to contribute positively and can serve as a strong 
indicator (value of $R$-Square $=50 \%$ ). Positive predictions can be viewed via a probe parameters ${ }_{Y}^{A}=30,98+2,875 X 3+$ eand significant. Value $T$-count $>T$-chart or $3.934>1.7033$ for the degrees of freedom (DF) $\alpha=0.05$.

Empathy can be seen that the partial variables can give the effect of increasing customer satisfaction and are able to contribute positively and can serve as a strong indicator (value of $R$-Square $=69 \%$ ). Positive predictions can be viewed via a probe parameters ${ }_{Y}^{a}=24,883+2,661 X 4+$ eand significant. Value $T$-count $>T$-chart or $4.111>1.7033$ for the degrees of freedom $(D F) \alpha=0.05$.

\section{Key Words}

Factor Tangible, Confidence, Reliability dan Empathy

\section{PENDAHULUAN}

PT. Garuda Indonesia merupakan salah satu perusahaan penerbangan nasional pertama di dalam negeri yang beroperasi dan berdiri pada tanggal 26 Januari 1949 dengan nama Indonesia Airways. Secara bertahap kegiatan penerbangannya semakin berkembang dan hingga menjadi perusahaan penerbangan yang terbesar di Indonesia.

Jasa yang dihasilkan dari kegiatan angkutan udara tersebut meliputi jasa penerbangan untuk penumpang/cargo ke berbagai daerah di Indonesia dan luar negeri. Tingkat persaingan jasa penerbangan ini sangat ketat dan sangat sensitif terhadap perubahan-perubahan kebijaksanaan baik internal maupun eksternal. Dalam usaha memenangkan persaingan memperebutkan pangsa pasar, setiap perusahaan penerbangan harus melihat prospek pasar angkutan udara dan berusaha untuk meningkatkan pelayanannya dan membuat suatu perencanaan strategi pemasaran dengan sebaik-baiknya.

Dewasa ini kegiatan angkutan udara komersil telah berkembang demikian pesatnya, sehingga setiap usaha penerbangan di Indonesia maupun di dunia berlomba untuk memenangkan persaingan dengan berbagai kiatnya. Salah satu upaya guna mencapai tujuan tersebut Garuda membuat strategi dengan pola Garuda Frequent Flyer Program (FFP). Kelebihan sebagai anggota GFF adalah sistem pencatatan mileage, penggunaan executive lounge, prioritas reservasi yang diberikan, fasilitas kelebihan bagasi sebesar $10 \mathrm{~kg}$, tiket cuma-cuma sesuai dengan mileage yang dikumpulkan, 
pelimpahan tiket cuma-cuma ke orang lain, up-grading ke kelas yang lebih tinggi dan bebas biaya pembatalan penerbangan. Bentuk-bentuk metamorfosa ini telah menjadikan para anggota FFP di suatu perusahaan penerbangan mempunyai tingkat ketergantungan yang tinggi dan makin banyak pihak intuisi bisnis yang dilibatkan maka tingkat ketergantungannya makin tinggi.

Dalam strategi pemasaran, untuk meningkatkan penjualan salah satu faktor yang perlu dipantau adalah tingkat kepuasan pelanggan. Dimana sangat tergantung pada kinerja karyawan, produk dan jasa pendukung (majalah bulanan Garuda) serta standar yang digunakan pelanggan untuk mengevaluasi kinerja. Dengan adanya pemantauan kepuasan pelanggan, diharapkan dapat menjadikan bahan evaluasi yang dapat dipertanggungjawabkan dalam hal pengambilan keputusan untuk mengembangkan produk lainnya, memenuhi proses pelayanan yang dibutuhkan untuk pelanggan dan perbaikan-perbaikan proses pelayanan kepada pelanggan. Pada akhirnya fasilitas pelayanan dapat meningkatkan tingkat kepuasan terhadap pelanggan.

\section{Rumusan Masalah}

Perumusan masalah yang akan dibahas oleh penulis adalah untuk menganalisis :

1. Faktor-faktor apa saja yang mempengaruhi kepuasan pelanggan terhadap fasilitas pelayanan di PT. Garuda Indonesia.

2. Seberapa besar faktor-faktor yang mempengaruhi kepuasan pelanggan terhadap fasilitas pelayanan di PT. Garuda Indonesia.

\section{TINJAUAN PUSTAKA}

Pemasaran merupakan salah satu kegiatan perekonomian yang utama selain kegiatan produksi dan konsumsi. Kegiatan pemasaran bukan hanya sekedar kegiatan yang meliputi jual beli saja akan tetapi juga berkaitan dengan berbagai permasalahan yang menyangkut kebutuhan dan keinginan konsumen.

Menurut Kohler (1997 : 8), pemasaran adalah suatu proses sosial dan manajerial yang di dalamnya individu dan kelompok mendapatkan apa yang mereka butuhkan dan 
inginkan dengan menciptakan, menawarkan, dan mempertukarkan produk yang bernilai dengan pihak lain.

Pelanggan akan memberikan penilaian atau evaluasi terhadap tingkat pelayanan yang dirasakan, berdasarkan atribut atau dimensi mengenai kualitas pelayanan, sebagaimana dijelaskan oleh Parasuraman, Zeithaml dan Berry (1991) :

1. Berwujud (Tangible), penampilan kualitas fisik, peralatan, personel dan media komunikasi.

2. Keyakinan (Confidence), pengetahuan dan kesopanan karyawan serta kemampuan mereka untuk menimbulkan kepercayaan dan keyakinan atau "assurance”.

3. Keandalan (Reliability), kemampuan untuk melaksanakan pelayanan yang dijanjikan dengan tepat dan terpercaya.

4. Empati (Empathy), syarat untuk peduli, memperhatikan pribadi bagi pelanggan.

\section{Kepuasan Pelanggan}

Menurut Kotler (1997 : 36), kepuasan pelanggan adalah perasaan senang atau kecewa seseorang yang berasal dari perbandingan antara kesannya terhadap kinerja (atau hasil) suatu produk dan harapan-harapannya.

Dalam meningkatkan tingkat kepuasan pelanggan, terdapat 5 faktor utama yang harus diperhatikan oleh perusahaan yaitu :

1. Kualitas Produk

Pelanggan akan merasa puas bila hasil evaluasi mereka menunjukkan bahwa produk yang mereka gunakan berkualitas.

2. Kualitas Pelayanan

Pelanggan akan merasa puas bila mereka mendapatkan pelayanan yang baik atau sesuai dengan apa yang diharapkan.

3. Emosional

Pelanggan akan merasa bangga dan mendapatkan keyakinan bahwa orang lain akan kagum terhadapnya bila menggunakan produk dengan merek tertentu yang cenderung mempunyai tingkatan kepuasan yang lebih tinggi.

4. Harga 
Produk yang mempunyai kualitas yang sama tetapi menetapkan harga yang relative murah akan memberikan nilai yang lebih tinggi kepada pelanggannya.

\section{Biaya}

Pelanggan yang tidak perlu mengeluarkan biaya tambahan atau tidak perlu membuang waktu untuk mendapatkan suatu produk atau jasa cenderung puas terhadap produk atau jasa itu.

\section{Pelayanan}

Pelayanan menurut Bennet (1995 : 444) yaitu kualitas yang menggambarkan tingkat minimum pelayanan yang ditentukan guna memuaskan keinginan pelanggan.

Kualitas pelayanan dapat ditinjau dari berbagai aspek diantaranya :

1. Alur pelayanan dalam bisnis wisata umumnya ditentukan dalam standar prosedur operational dan perlu adanya adaptasi terhadap lingkungan.

2. Waktu dalam pelayanan dapat diartikan kecepatan dan ketepatan.

3. Antisipasi pada setiap kebutuhan wisatawan harus selalu dilakukan oleh industri pariwisata.

4. Komunikasi dapat berlangsung setiap saat, dimana saja, kapan saja, oleh siapa saja, dan dengan siapa saja. Komunikasi merupakan kegiatan yang penuh dengan interaksi antar manusia, media yang dibutuhkan untuk pemberi jasa dan penerima jasa.

5. Tanggapan langganan dibutuhkan untuk memberikan gambaran kepuasan pelayanan, bentuknya sangat bervariasi baik secara lisan, tulisan maupun melalui tindakan.

6. Pengawasan dilakukan untuk menjaga kualitas pelayanan, yang bertujuan untuk menemukan kebutuhan dan keinginan antara pemberi jasa dan penerima jasa. 


\section{METODOLOGI PENELITIAN}

\section{Teknik Pengumpulan Data}

\section{a. Data Primer}

1. Kuesioner/angket, adalah teknik dengan menggunakan instrument pengumpul data, dimana terjadi wawancara dan tatap muka langsung dengan responden.

2. Wawancara, adalah teknik dengan mengajukan pertanyaan secara lisan/tatap muka langsung antara pengumpul data dengan responden.

3. Dokumentasi, adalah teknik bahan tertulis (dokumen) yang berhubungan dengan masalah yang diteliti.

\section{b. Data Sekunder}

Data pendukung atau pelengkap data primer yang dikumpulkan oleh pihak lain yang berkaitan dengan permasalahan yang diteliti. Hasil data diproses melalui program SPSS 2007.

\section{Teknik Analisis Data}

Dalam penelitian ini menggunakan uji model ganda (uji simultan), sebagaimana diformulasikan $\stackrel{a}{=}=a+b 1 X 1+b 2 X 2+b 3 X 3+b 4 X 4+e$

Keterangan :

$$
\begin{array}{ll}
Y & : \text { Variabel dependent } \\
\text { a } & : \text { Konstanta model } \\
\text { b1,b2,b3 dan b4 } & : \text { Koefisien Variabel Independent } \\
\mathrm{X} 1, \mathrm{X} 2, \mathrm{X} 3 \text {, dan X4 } & \text { : Variabel Independent }
\end{array}
$$

Serta untuk parameter uji regresi parsial dapat diminimaize melalui pendekatan "OLS" (Ordinary Least Square) melalui :

$$
\stackrel{a}{=}=a+b X+e
$$

Keterangan :

$Y \quad$ : Variabel Dependent

a : Konstanta

b : Koefisien Variabel Independent 
X : Variabel Independent

Dalam uji validitas digunakan perhitungan Korelasi Product Moment dalam uji rkritisnya (Suharsini Arikunto, 1997, p. 57), yaitu :

$$
r_{x y}=\frac{n\left(\sum X Y\right)-\left(\sum X\right)\left(\sum Y\right)}{\sqrt{\left\{n \cdot\left(\sum_{X} 2\right)-\left(\sum X\right)^{2}\right\}\left\{n \cdot\left(\sum_{Y} 2\right)-\left(\sum Y\right)^{2}\right\}}}
$$

Keterangan :

rxy : Koefisien korelasi (r hitung)

x : Instrumen indikator (kuesioner)

y : Variabel yang bersangkutan

n : Jumlah sampel

Untuk menguji signifikansi dari model yang dijelaskan, dapat dilakukan pengujian model penduga $\mathrm{T}$ hitung dan $\mathrm{F}$ hitung layaknya yang diformulasikan, sebagai berikut :

$$
\begin{aligned}
T h & =\frac{r X Y \sqrt{n-2}}{\sqrt{1-r}} \\
F h & =\frac{S S Y}{S S(Y-Y) /(n-2)}
\end{aligned}
$$

Sebagai estimasi penggunaan dapat dijelaskan sebagai berikut :

- Apabila Th atau Fh $>$ T table atau F table untuk $\alpha$ 0,05 maka terjadi penolakan Ho (berkategori one fail test).

- Sebaliknya, apabila Th atau Fh $\leq \mathrm{T}$ table atau F table untuk $\alpha$ 0,05 maka terjadi penerimaan Ho (berkategori one fail test).

\section{ANALISIS DATA}

\section{Pengujian Hipotesis}

1.Hubungan antara faktor tangible (berwujud), confidence (keyakinan), reliability (keandalan) dan empathy (empati) dari jasa pelayanan yang diberikan terhadap tingkat kepuasan pelanggan pemegang GFF di PT. Garuda Indonesia

\section{Persamaan Regresi}


Dari hasil pengolahan data yang menggunakan program SPSS diperoleh persamaan :

$\stackrel{A}{Y}=0,982+1,07 X 1+0,947 X 2+0,98 X 3+0,955 X 4+e$

\section{$\underline{\text { Koefisien Determinasi }}$}

Melalui hasil penelitian ternyata masing-masing variabel tersebut dapat memberikan kontribusi secara simultan sebesar 0,991.

\section{Pengujian Tingkat Signifikansi}

Dari hasil pengolahan data diperoleh nilai F hitung > F table atau 712,227 > 2,557. Dengan demikian kemaknaan hubungan antara variabel independent dengan variabel dependent bermakna atau signifikan.

\section{Hasil Uji Hipotesis}

Menjelaskan bahwa ke 4 (empat) faktor tersebut dapat memebrikan kontribusi yang sangat kuat dan positif terhadap peningkatan kepuasan pelanggan GFF. Dapat dipertegas bahwa dari hipotesis alternatif (Ha) dapat diterima secara nyata dan signifikan atau dengan kata lain terjadi penolakan hipotesis nol (Ho).

\section{Hubungan antara faktor Tangible (Berwujud) dari jasa pelayanan yang diberikan terhadap tingkat kepuasan pelanggan pemegang GFF di PT. Garuda Indonesia \\ $\underline{\text { Korelasi }}$}

Dari hasil pengolahan data diperoleh nilai koefisien korelasi sebesar 0,899 atau nilai Rho sebesar $89,9 \%$.

\section{Nilai Koefisien Determinasi}

Dari hasil pengolahan data diperoleh nilai koefisien determinasi sebesar $0,808(80,8 \%)$.

\section{Prediksi}

Dari hasil pengolahan data menggunakan program SPSS diperoleh persamaan :

$\stackrel{\mathrm{A}}{\mathrm{Y}}=23,036+2,371 X 1+e$

Dengan demikian prediksi ke depannya PT. Garuda Indonesia, apabila tidak melakukan upaya peningkatan variabel tangible (berwujud) maka sesungguhnya sudah ada nilai kepuasan sebesar 23,036, tetapi apabila dilakukan upaya peningkatan variabel tangible (berwujud) maka kepuasan pelanggan secara positif akan memberikan kontribusi terhadap upaya peningkatan kepuasan pelanggan sebesar 2,371 satuan.

\section{Pengujian Tingkat Signifikansi}


Dari hasil pengolahan data diperoleh nilai $\mathrm{T}$ hitung sebesar 4,964, sedangkan $\mathrm{T}$ tabel sebesar 1,7033. Dengan demikian bahwa nilai T hitung lebih besar dari pada $\mathrm{T}$ tabel, hal tersebut memberikan arti bahwa hubungan antara faktor tangible (berwujud) dengan kepuasan pelanggan signifikan.

\section{Pengujian Hipotesis}

Diduga terdapat hubungan yang positif dan signifikan antara faktor tangible (berwujud) terhadap kepuasan pelanggan GFF.

\section{Parameter Kuantitatif Pengaruh faktor Tangible (Berwujud) Terhadap Kepuasan Pelanggan}

\begin{tabular}{|c|c|c|c|c|c|}
\hline Hubungan & PARAI & ETER & & & $\alpha$ \\
\hline Variabel & Rho & Rsq & T hitung & $\mathrm{T}$ tabel & \\
\hline$Y-->X 1$ & 0,899 & 0,808 & 4,964 & 17,033 & $5 \%$ \\
\hline Prediksi & & & $3,036+2$ & $71 X 1+e$ & \\
\hline Pengujian S & ifikan & & & & \\
\hline T hitung $>1$ & bel $=4$ & $64>1$ & & & \\
\hline
\end{tabular}

Sumber : Data lapangan, diolah dengan SPSS

Keterangan ;

$Y \quad$ : Kepuasan Pelanggan

X1 : Variabel Tangible (berwujud)

3.Hubungan antara faktor Confidence (Keyakinan) dari jasa pelayanan yang diberikan terhadap tingkat kepuasan pelanggan pemegang GFF di PT. Garuda

\section{Indonesia}

\section{Korelasi}

Dari hasil pengolahan data diperoleh nilai koefisien korelasi sebesar 0,828 atau nilai Rho sebesar $82,8 \%$. 


\section{$\underline{\text { Nilai Koefisien Determinasi }}$}

Dari hasil pengolahan data diperoleh nilai koefisien determinasi sebesar 0,686 $(68,6 \%)$.

\section{Prediksi}

Dari hasil pengolahan data menggunakan program SPSS diperoleh persamaan :

$\stackrel{a}{Y}=12,159+3,182 \times 2+e$

Dengan demikian prediksi kedepannya PT. Garuda Indonesia, apabila tidak melakukan upaya peningkatan variabel confidence (keyakinan) maka sesungguhnya sudah ada nilai kepuasan sebesar 23,036, tetapi apabila dilakukan upaya peningkatan variabel confidence (keyakinan) maka kepuasan pelanggan secara positif akan memberikan kontribusi terhadap upaya peningkatan kepuasan pelanggan sebesar 2,371 satuan.

\section{Pengujian Tingkat Signifikansi}

Dari hasil pengolahan data diperoleh nilai $\mathrm{T}$ hitung sebesar 1,550, sedangkan $\mathrm{T}$ table sebesar 1,7033. Dengan demikian bahwa nilai T hitung lebih besar dari pada $\mathrm{T}$ table, hal tersebut memberikan arti bahwa hubungan antara faktor confidence (keyakinan) dengan kepuasan pelanggan signifikan.

\section{Pengujian Hipotesis}

Diduga terdapat hubungan yang positif dan signifikan antara faktor confidence (keyakinan) terhadap kepuasan pelanggan GFF.

\section{Parameter Kuantitatif Pengaruh faktor Confidence (Keyakinan) Terhadap Kepuasan Pelanggan}

\begin{tabular}{|c|c|c|c|c|c|}
\hline \multirow{2}{*}{$\begin{array}{l}\text { Hubungan } \\
\text { Variabel }\end{array}$} & \multicolumn{4}{|c|}{ PARAMETER } & \multirow[t]{2}{*}{$\alpha$} \\
\hline & Rho & Rsq & T hitung & T tabel & \\
\hline$Y-->X 2$ & 0,828 & 0,686 & 1,550 & 1,7033 & $5 \%$ \\
\hline $\begin{array}{l}\text { Prediksi } \\
\text { Pengujian } \\
\text { Signifikan }\end{array}$ & & & $a^{a}-12$ & & \\
\hline T hitung $>$ & abel = & $50>1$ & & & \\
\hline
\end{tabular}

Sumber : Data lapangan, diolah dengan SPSS 
Keterangan ;

$Y \quad$ : Kepuasan Pelanggan

X2 : Variabel Confidence (Keyakinan)

4.Hubungan antara faktor Reliability (Keandalan) dari jasa pelayanan yang diberikan terhadap tingkat kepuasan pelanggan pemegang GFF di PT. Garuda Indonesia

\section{Korelasi}

Dari hasil pengolahan data diperoleh nilai koefisien korelasi sebesar 0,711 atau nilai Rho sebesar $71,1 \%$.

\section{Nilai Koefisien Determinasi}

Dari hasil pengolahan data diperoleh nilai koefisien determinasi sebesar 0,506 (50,6\%).

\section{Prediksi}

Dari hasil pengolahan data menggunakan program SPSS diperoleh persamaan :

${ }_{Y}^{\mathrm{a}}=30,98+2,875 X 3+e$

Dengan demikian prediksi kedepannya PT. Garuda Indonesia, apabila tidak melakukan upaya peningkatan variabel reliability (keandalan) maka sesungguhnya sudah ada nilai kepuasan sebesar 30,98 tetapi apabila dilakukan upaya peningkatan variabel reliability (keandalan) maka kepuasan pelanggan secara positif akan memberikan kontribusi terhadap upaya peningkatan kepuasan pelanggan sebesar 2,785 satuan.

\section{Pengujian Tingkat Signifikansi}

Dari hasil pengolahan data diperoleh nilai $\mathrm{T}$ hitung sebesar 3,934, sedangkan $\mathrm{T}$ table sebesar 1,7033. Dengan demikian bahwa nilai T hitung lebih besar dari pada T table, hal tersebut memberikan arti bahwa hubungan antara faktor reliability (keandalan) dengan kepuasan pelanggan signifikan.

\section{Pengujian Hipotesis}

Diduga terdapat hubungan yang positif dan signifikan antara faktor reliability (keandalan) terhadap kepuasan pelanggan GFF. 


\section{Parameter Kuantitatif Pengaruh faktor Reliability (Keandalan) Terhadap Kepuasan Pelanggan}

\begin{tabular}{|c|c|c|c|c|c|}
\hline \multirow{2}{*}{$\begin{array}{l}\text { Hubungan } \\
\text { Variabel }\end{array}$} & \multicolumn{4}{|c|}{ PARAMETER } & \multirow[t]{2}{*}{$\alpha$} \\
\hline & Rho & Rsq & T hitung & T tabel & \\
\hline$Y-->X 3$ & 0,711 & 0,506 & 3,934 & 1,7033 & $5 \%$ \\
\hline \multicolumn{6}{|l|}{ Prediksi } \\
\hline \multicolumn{6}{|l|}{ Pengujian } \\
\hline T hitung > & abel = & $34>1$ & & & \\
\hline
\end{tabular}

Sumber : Data lapangan, diolah dengan SPSS

Keterangan ;

$Y \quad$ : Kepuasan Pelanggan

X3 : Variabel Reliability (Keandalan)

5.Hubungan antara faktor Empathy (Empati) dari jasa pelayanan yang diberikan terhadap tingkat kepuasan pelanggan pemegang GFF di PT. Garuda Indonesia

\section{Korelasi}

Dari hasil pengolahan data diperoleh nilai koefisien korelasi sebesar 0,835 atau nilai Rho sebesar $83,5 \%$.

\section{Nilai Koefisien Determinasi}

Dari hasil pengolahan data diperoleh nilai koefisien determinasi sebesar 0,697 (69,7\%).

\section{$\underline{\text { Prediksi }}$}

Dari hasil pengolahan data menggunakan program SPSS diperoleh persamaan :

$\stackrel{a}{Y}=24,883+2,661 X 4+e$

Dengan demikian prediksi ke depannya PT. Garuda Indonesia, apabila tidak melakukan upaya peningkatan variabel empathy (empati) maka sesungguhnya sudah ada nilai kepuasan sebesar 24,833 tetapi apabila dilakukan upaya peningkatan variabel empathy 
(empati) maka kepuasan pelanggan secara positif akan memberikan kontribusi terhadap upaya peningkatan kepuasan pelanggan sebesar 2,661 satuan.

\section{Pengujian Tingkat Signifikansi}

Dari hasil pengolahan data diperoleh nilai $\mathrm{T}$ hitung sebesar 4,111, sedangkan $\mathrm{T}$ table sebesar 1,7033. Dengan demikian bahwa nilai T hitung lebih besar dari pada $\mathrm{T}$ table, hal tersebut memberikan arti bahwa hubungan antara faktor empathy (empati) dengan kepuasan pelanggan signifikan.

\section{Pengujian Hipotesis}

Diduga terdapat hubungan yang positif dan signifikan antara faktor empathy (empati) terhadap kepuasan pelanggan GFF.

\section{Parameter Kuantitatif Pengaruh faktor Empathy (Empati) Terhadap Kepuasan Pelanggan}

\begin{tabular}{|c|c|c|c|c|c|}
\hline \multirow{2}{*}{$\begin{array}{l}\text { Hubungan } \\
\text { Variabel }\end{array}$} & \multicolumn{4}{|c|}{ PARAMETER } & \multirow[t]{2}{*}{$\alpha$} \\
\hline & Rho & Rsq & T hitung & T tabel & \\
\hline$Y-->X 4$ & 0,835 & 0,697 & 4,111 & 1,7033 & $5 \%$ \\
\hline \multicolumn{4}{|l|}{ Prediksi } & & \\
\hline \multicolumn{6}{|l|}{ Pengujian } \\
\hline \multicolumn{6}{|l|}{ Signifikan } \\
\hline \multicolumn{6}{|c|}{ T hitung $>\mathrm{T}$ tabel $=4,111>1,7033$} \\
\hline
\end{tabular}

Sumber : Data lapangan, diolah dengan SPSS

Keterangan ;

$Y \quad$ : Kepuasan Pelanggan

X4 : Variabel Empathy (Empati) 


\section{KESIMPULAN}

Dari hasil penelitian terhadap .. orang responden menunjukkan bahwa :

1. Faktor Tangible (berwujud), Confidence (keyakinan), Reliability (keandalan) dan Empathy (empati) memberikan upaya peningkatan kepuasan pelanggan GFF, yang selanjutnya melalui persamaan secara simultan dicerminkan ${ }_{\mathrm{Y}}^{\mathrm{A}}=0,892+1,07 \mathrm{X} 1+0,947 \mathrm{X} 2+0,98 \times 3+0,955 \times 4+$ e dan kontribusinya sebesar 0,98 atau $98 \%$.

2. Faktor tangible (berwujud) yang dicerminkan dengan keberadaan fasilitas pendukung akan memberikan upaya peningkatan kepuasan pelanggan GFF, yang selanjutnya faktor tangible melalui persamaan secara parsial dicerminkan ${ }_{Y}^{A}=23,036+2,371 X 1+e$ dan kontribusinya sebesar 0,808 atau $80,8 \%$.

3. Faktor confidence (keyakinan) yang dicerminkan dengan keyakinan pelanggan terhadap jaminan pelayanan juga dianggap sangat penting terhadap upaya peningkatan kepuasan pelanggan GFF, yang selanjutnya faktor confidence melalui persamaan secara parsial dicerminkan ${ }_{Y}^{\wedge}=12,159+3,18 X 2+e$ dan kontribusinya sebesar 0,68 atau $68 \%$.

4. Faktor reliability (keandalan) yang dicerminkan dengan keyakinan pelanggan terhadap jaminan pelayanan juga dianggap sangat penting terhadap upaya peningkatan kepuasan pelanggan GFF, yang selanjutnya faktor reliability melalui persamaan secara parsial dicerminkan ${ }_{Y}^{n}=30,98+2,875 \times 3+e$ dan kontribusinya sebesar 0,50 atau $50 \%$.

5. Faktor empathy (empati) yang dicerminkan dengan keyakinan pelanggan terhadap jaminan pelayanan juga dianggap sangat penting terhadap upaya peningkatan kepuasan pelanggan GFF, yang selanjutnya faktor empathy melalui persamaan secara parsial dicerminkan ${ }_{Y}^{\wedge}=24,883+2,661 X 4+e$ dan kontribusinya sebesar 0,69 atau $69 \%$.

\section{SARAN}

PT. Garuda Indonesia harus mampu lebih berupaya meningkatkan faktor-faktor tangible (berwujud), confidence (keyakinan), reliability (keandalan) dan empathy (empati) agar kepuasan akan pelanggannya dapat terus meningkat. 


\section{DAFTAR PUSTAKA}

Corporate Communication PT. Garuda Indonesia (JKTICGA), 1997, Corporate Profile, Jakarta.

Organisasi dan Kualitas Perencanaan Perusahaan PT. Garuda Indonesia (JKTIQGA), 1998, Panduan Monitor Kualitas dan Pelayanan PT. Garuda Indonesia, Jakarta.

Kotler, Philip, 1997, Manajemen Pemasaran: Analisis, Perencanaan, Implementasi dan Kontrol (Edisi Bahasa Indonesia), Jakarta.

Lupiyoadi, Rambat, 2001, Manajemen Pemasaran Jasa Teori dan Praktik, Salemba Empat, Jakarta.

Sugiarto, Endar, 1999, Psikologi Pelayanandalam Industri Jasa, PT. Gramedia Pustaka Utama, Jakarta.

Supranto, J, 1997, Pengukuran Tingkat Kepuasan Pelanggan untuk Menaikkan Pangsa Pasar Edisi Pertama, Reneka Cipta, Jakarta.

Ciptono, Fandi, Diana dan Anastasia, 2001, Total Quality Manajemen Edisi Revisi, Yogyakarta.

Ciptono, Fandi, 2001, Prinsip-Prinsip Total Quality Service, PT. Andi, Yogyakarta. 